\title{
Qualidade da madeira de mogno africano para a produção de serrados
}

\author{
Wood quality of African mahogany for lumber production
}

\author{
João Gabriel Missia da Silva ${ }^{1}$, Graziela Baptista Vidaurre ${ }^{2}$, Marina Donária Chaves Arantes ${ }^{2}$, \\ Djeison Cesar Batista ${ }^{2}$, Denise Ransolin Soranso ${ }^{1}$ e Dâmaris Figueiredo Billo ${ }^{3}$
}

\begin{abstract}
Resumo
O objetivo deste trabalho foi avaliar a deformação residual longitudinal, o índice de rachaduras (de topo de toras e tábuas), o deslocamento da medula e os defeitos de secagem nas tábuas das espécies de Khaya ivorensis e Khaya senegalensis para a produção de madeira serrada. O material foi proveniente de um plantio experimental em Linhares, ES, Brasil, sendo utilizadas cinco árvores por espécie, com 19 anos de idade. Com as árvores em pé foi realizada a leitura da deformação residual longitudinal, utilizando o método CIRAD - Forêt. Após o corte das árvores, os topos inferiores das toras da base foram fotografados para a mensuração das rachaduras e do deslocamento da medula. As rachaduras de topo e os empenamentos das tábuas também foram mensurados, após a secagem. No geral, não houve diferenças significativas nas médias de deformação residual longitudinal, índice de rachaduras de toras e tábuas e deslocamento da medula entre as espécies. Todavia, a espécie Khaya ivorensis apresentou as maiores dimensões de rachaduras de topo de toras e de tábuas, enquanto, as tábuas de Khaya senegalensis apresentaram os maiores empenamentos. Os índices das variáveis avaliadas não são elevados ao ponto de inviabilizar o uso e a qualidade das duas espécies de mogno africano para a produção de madeira serrada, sendo importante ponderar, principalmente, a forma e dimensões das árvores e os defeitos da madeira serrada em regiões mais próximas da medula e em idades mais jovens.
\end{abstract}

Palavras-chave: Khaya, Deformação residual longitudinal, Rachaduras, Defeitos da madeira serrada.

\begin{abstract}
The aim of this work was to evaluate the longitudinal residual strain, the index of splits (end of logs and boards), the displacement of the pith and the drying defects on the boards of the species of Khaya ivorensis and Khaya senegalensis for lumber production. The material comes from an experimental plantation in Linhares, ES, Brazil, with five trees per species being utilized, at age 19 years. The reading of the longitudinal residual strain using the method CIRAD - Forêt on standing trees was taken. After cutting of the trees, the end of logs was photographed for measurement of splits and displacement of the pith. The end splits and warping of the boards were also measured, after drying. Overall, there were not statistical differences in longitudinal residual strain, index split of logs and boards and displacement of the pith between species. However, Khaya ivorensis showed the larger dimensions of end split logs and boards, while, the boards of Khaya senegalensis had higher warping. The indexes of the variables are not high to the point of rendering unfeasible the use and the wood quality of the two species of African mahogany for the lumber production. It is important to consider, however, the shape and dimensions of trees and lumber defects in regions closest of the pith and at younger ages.
\end{abstract}

Keywords: Khaya, Longitudinal residual strain, Splits, Lumber defects.

\section{INTRODUÇÃO}

Os plantios de mogno africano têm aumentado no Brasil nos últimos anos, com o objetivo de atender a demanda crescente por madeira para produtos sólidos. Sob a mesma denominação de mogno africano, são comercializadas no país mudas de três espécies: a Khaya ivorensis (mais utilizada em plantios comerciais), a Khaya senegalensis e a Khaya anthotheca.

\footnotetext{
${ }^{1}$ Doutorando(a) em Ciências Florestais. UFES - Universidade Federal do Espírito Santo / Centro de Ciências Agrárias. Avenida Governador Lindemberg, 31 - 29550000 - Jerônimo Monteiro, ES, Brasil. E-mail: j.gabrielmissia@hotmail.com; denise soranso@hotmail.com

2Professor(a) Adjunto do Departamento de Ciências Florestais. UFES - Universidade Federal do Espírito Santo / Centro de Ciências Agrárias. Avenida Governador Lindemberg, 31 - 29550000 - Jerônimo Monteiro, ES, Brasil. E-mail: grazividaurre@gmail.com; mdonariac@hotmail.com; djeison.batista@ufes.br

${ }^{3}$ Graduanda em Engenharia Industrial Madeireira. UFES - Universidade Federal do Espírito Santo / Centro de Ciências Agrárias. Avenida Governador Lindemberg, 31 - 29550000 - Jerônimo Monteiro, ES, Brasil. E-mail: damaris billo@hotmail.com
} 
Como esses plantios ainda estão em desenvolvimento, não existe madeira disponível em larga escala no mercado interno brasileiro. Por isso, o valor da madeira serrada é determinado de acordo com os preços e qualidade das madeiras comercializadas no mercado internacional de origem nativa e em idade mais avançada, e comparativamente aos de outras espécies brasileiras tradicionais.

Considerando que no Brasil, a expectativa de comércio da madeira do mogno africano é com aproximadamente 15 a 20 anos de idade, com desbastes ao longo do ciclo de rotação, a madeira que será ofertada poderá conter uma grande proporção de lenho juvenil, má formação do fuste e níveis altos de tensões de crescimento, contribuindo para defeitos durante o processamento e utilização, que comprometerão a qualidade, consequentemente a classificação, o aproveitamento, a competitividade e o valor final dessa madeira.

Os principais usos da madeira de mogno africano são a movelaria, a produção de lâminas decorativas e instrumentos musicais, a construção naval e a arquitetura de interiores. Para a maioria destes produtos, as toras precisam ser desdobradas, e as espécies que apresentam boa forma do fuste, baixos níveis de tensões de crescimento, rachaduras e empenamentos, proporcionará maiores índices de aproveitamento da madeira.

Nesta conjuntura, há necessidade de pesquisas sobre a qualidade da madeira de mogno africano oriunda de plantações florestais no país, em idades jovens, averiguando a magnitude das deformações residuais longitudinais, decorrentes das tensões de crescimento e suas relações com os defeitos das toras e peças serradas; as relações das características de crescimento das árvores com as propriedades do lenho e defeitos da madeira serrada; e outras particularidades. Essas informações poderão subsidiar programas de melhoramento genético das espécies, contribuir para o ajuste de processos tecnológicos e dos produtos, e por fim o desenvolvimento das espécies do gênero Khaya no Brasil.

A deformação residual longitudinal e o índice de rachaduras de topo de toras, indicadores das tensões de crescimento, encontram-se entre os principais parâmetros utilizados para a avaliação da qualidade de toras e de diferentes materiais genéticos para uso em serrarias (LIMA; GARCIA; PIEDADE, 2002; LIMA et al., 2004; FRANÇA, 2014). Em adição a esses parâmetros, a avaliação de defeitos nas tábuas permite delinear, de forma trivial, o potencial de espécies florestais para a produção de madeira serrada.

A espécie Khaya ivorensis pode apresentar sapopemas e cancro (Lasiodiplodia theobromae), possui uma menor conicidade do fuste e copas mais amplas em relação à espécie Khaya senegalensis. Prontamente, árvores dessa última espécie exibem, com frequência, bifurcações no tronco e maior espessura da casca, quando comparada às arvores de Khaya ivorensis. Essas duas espécies, plantadas na região Norte do estado do Espírito Santo, apresentam boa desrama natural, semelhanças quanto ao fator de forma e madeira com cerne pouco distinto do alburno.

O objetivo deste trabalho foi avaliar a deformação residual longitudinal, o índice de rachaduras (de topo de toras e tábuas), o deslocamento da medula e os defeitos de secagem nas tábuas de duas espécies de mogno africano para a produção de madeira serrada.

\section{MATERIAL E MÉTODOS}

Sítio e amostragem experimental: as espécies de mogno africano estudadas foram a Khaya ivorensis A. Chev. e a Khaya senegalensis (Desr.) A. Juss. (19 anos), provenientes de um mesmo plantio experimental da Reserva Natural Vale, Linhares, Espírito Santo, Brasil (19०0 $06^{\prime}$ a $19^{\circ} 18^{\prime} \mathrm{S}$ e $39^{\circ} 45^{\prime}$ a $40^{\circ} 19^{\prime} \mathrm{W}$ ).

O relevo da Reserva Natural Vale é relativamente plano com altitude que varia de 28 a $65 \mathrm{~m}$, sendo o solo predominante o argissolo amarelo. O clima do local, segundo a classificação de Köppen é do tipo Aw (tropical úmido), com estação chuvosa no verão e seca no inverno. Os indivíduos cresceram anualmente sob uma pluviosidade média de $1200 \mathrm{~mm}$, temperatura média de $25,08{ }^{\circ} \mathrm{C}$ e umidade relativa do ar de $82,9 \%$.

O espaçamento inicial de plantio foi de $2 \times 3 \mathrm{~m}$, em uma área útil de 0,15 ha. No momento do plantio foram aplicados $200 \mathrm{~g}$ de superfosfato simples por cova. Os lotes de sementes foram provenientes de Burkina-Faso e Senegal para a espécie K. senegalensis e da França para a espécie K. ivorensis.

Foram coletadas cinco árvores de cada espécie, que previamente tiveram, a altura comercial (considerada até a inserção do primeiro galho ou bifurcação) mensurada com o auxílio do hipsômetro Vertex IV, e o diâmetro à altura do peito (DAP) mensurado com o auxílio de suta. 
Deformação residual longitudinal (DRL): a medição da DRL foi realizada na altura do DAP [Figura 1 (A)], considerando as direções cardeais norte e sul, em momentos de ausência de vento, conforme a metodologia do Centre de Coopération Internationale em Recherche Agronomique pour le Développement, Département dês Forêt (CIRAD - Forêt). Para tal, utilizou-se um relógio comparador digital, comumente chamado de extensômetro (Growth Strain Gauge), conforme descrito por Beltrame et al. (2013).

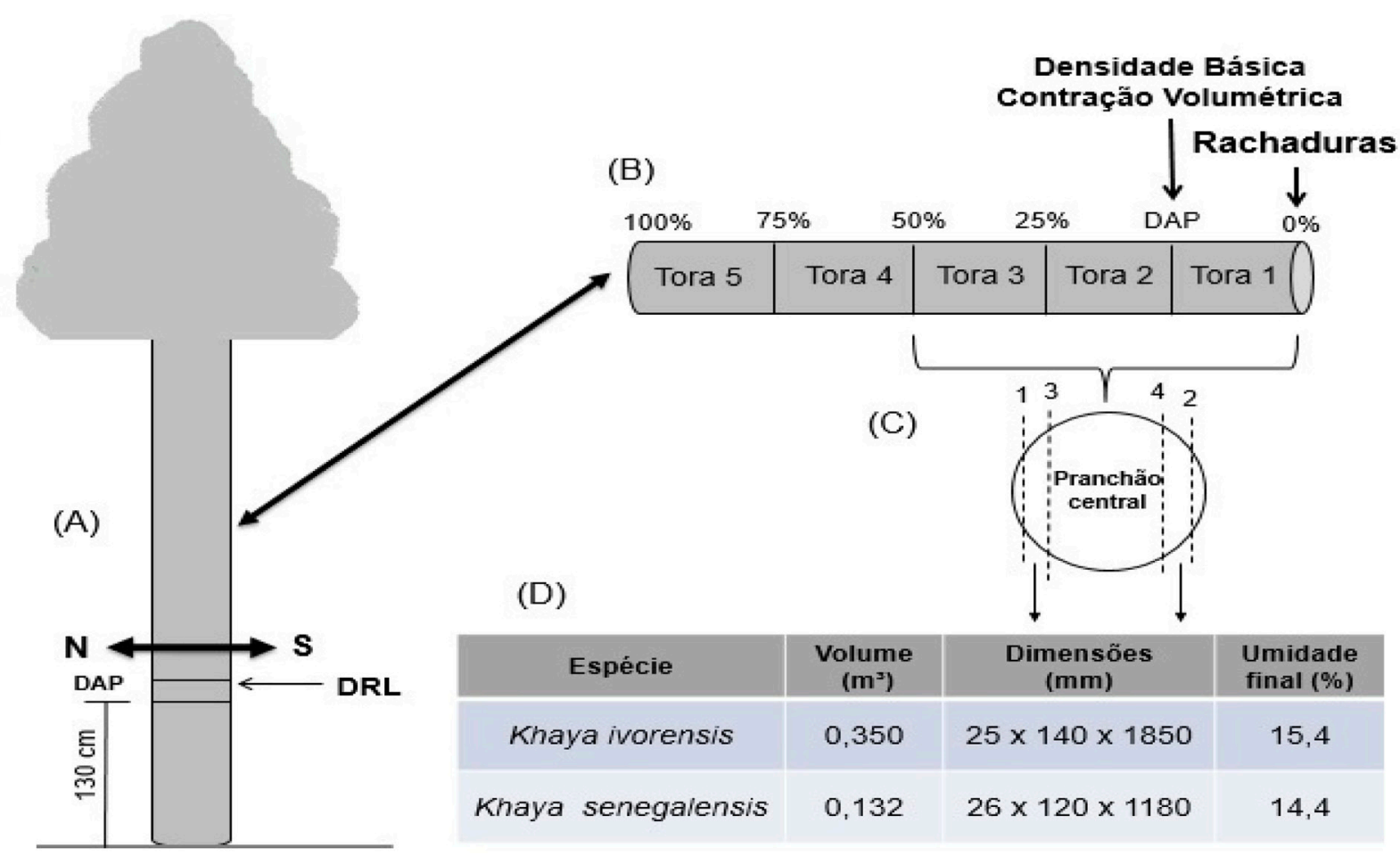

Figura 1. Amostragem e pontos de análises: $D R L$ com árvore em pé (A); amostragem do fuste (B); modelo de corte (C); características das tábuas (D).

Figure 1. Sampling and analyzes points: LRS with standing tree (A); sampling of the stem (B); sawing diagram (C); characteristics of the boards (D).

Índice de Rachaduras de Topo de Toras (IRTT) e Deslocamento da Medula (DM): para a mensuração das dimensões das rachaduras de topo das toras foi adotada a metodologia proposta por Schaitza, Mattos e Pereira (2003). Apenas o topo da base da primeira tora das árvores [Figura 1 (B)] foi fotografado, logo após o corte, posicionando a câmera em uma distância padrão de $1 \mathrm{~m}$ na direção do eixo longitudinal da tora. Desta forma, foi possível obter as dimensões (abertura e comprimento) das rachaduras de topo e o deslocamento da medula, por meio do software Image J (versão 1.47). O IRTT foi calculado de acordo com a metodologia "P", proposta por Lima, Garcia e Piedade (2002), considerando o somatório da área das rachaduras em relação ao diâmetro da tora, e o DM seguindo o método utilizado por Lima, Garcia e Stape (2007).

Ressalva-se que, somente as rachaduras da primeira tora de cada árvore foram avaliadas, por causa do diâmetro médio ser superior a $25 \mathrm{~cm}$, de acordo com o que é aceito para a produção de madeira serrada.

Rachaduras de topo e empenamentos de tábuas após o processo de secagem: as três primeiras toras de cada árvore foram desdobradas, produzindo-se um pranchão central ( $80 \mathrm{~mm}$ de espessura) e tábuas tangenciais (25 mm de espessura) [Figura 1 (B), (C) e (D)]. Pelo menos duas tábuas foram desdobradas de cada tora e, eventualmente, três ou quatro (máximo), de acordo com o diâmetro. As tábuas foram refiladas e empilhadas para secagem natural, atingindo a umidade de equilíbrio da região (16\%) em 172 dias. O índice de rachaduras de topo de tábuas após a secagem (IRTS), o encurvamento e arqueamento foram medidos em seguida, conforme a Norma Brasileira Regulamentadora - NBR 9487 (ABNT, 1986).

Densidade básica (DB) e contração volumétrica total (CV): para a determinação das propriedades físicas do lenho, foram utilizados os discos da altura do DAP [Figura 1 (B)] de todas as árvo- 
res, dos quais foram retirados corpos de prova de $2 \times 2 \times 1 \mathrm{~cm}^{3}$ (longitudinal, tangencial e radial), a cada centímetro ao longo do seu diâmetro. A DB e a CV foram determinadas conforme a NBR 7190 (ABNT, 1997).

Análise estatística: o experimento foi realizado em delineamento inteiramente casualizado, tendo como tratamentos as duas espécies (K. ivorensis e K. senegalensis) e o nível de significância adotado para todos os testes foi de $5 \%$ de probabilidade.

Foi aplicado o teste t de Student ao conjunto de dados (DRL, IRTT, DM, IRTS, arqueamento, encurvamento, DB e CV) dos dois tratamentos, para verificar a existência, ou não, de diferença entre eles. Antes desta análise, foi testada a homogeneidade das variâncias.

Para variáveis com valores em porcentagem (IRTT, IRTS, arqueamento e encurvamento), verificou-se a necessidade de transformação dos dados originais pelo teste de normalidade de variância (Shapiro-Wilk), para isso, utilizou-se a transformação potência (BOX; COX, 1964), demonstrada na Equação 1.

$$
\mathrm{DT}=\left(\frac{\mathrm{do}^{0,2}-1}{0,3176}\right)+2
$$

Em que: DT: Dado Transformado; do: Dado Original, \%.

A relação entre as variáveis estudadas foi analisada por meio do coeficiente de correlação linear de Pearson e seu valor P.

\section{RESULTADOS E DISCUSSÃO}

A altura comercial das árvores de mogno africano apresentou uma diferença expressiva, comum em indivíduos de propagação seminífera, onde a espécie K. ivorensis manifestou o maior crescimento, média de 14,94 m, comparado aos 8,21 m das árvores de K. senegalensis, uma diferença de 45\%. O DAP médio $(25 \mathrm{~cm})$ das árvores de ambas as espécies foi semelhante. Considerando que o fator de forma $(0,71)$ das espécies foi similar, a espécie $K$. ivorensis proporcionou um maior volume de madeira para laminação ou serraria, principalmente, por causa da altura e ausência de bifurcações no fuste.

DRL: a deformação residual longitudinal não diferenciou, significativamente, entre as duas espécies de mogno africano, e nem entre os pontos cardeais (norte e sul) de leitura (Tabela 1), fato também observado por Lima et al. (2004); França (2014), para o gênero Eucalyptus, em diferentes idades.

Tabela 1. Valores médios de deformação residual longitudinal, índice de rachaduras de topo de toras e tábuas, deslocamento da medula e empenamentos da madeira de $K$. ivorensis e $K$. senegalensis aos 19 anos de idade.

Table 1. Mean values of longitudinal residual strain, index end splits of logs and boards, displacement of the pith and warping of the wood of 19 -year-old $K$. ivorensis and $K$. senegalensis.

\begin{tabular}{lcccccc}
\hline Espécie & ${ }^{*}$ DRL mm & IRTT \% & DM cm & IRTS \% & ENC \% & ARQ \% \\
\hline \multirow{2}{*}{ K. ivorensis } & $0,082^{\text {ns }}$ & $0,20^{\text {ns }}$ & $2,17^{\text {ns }}$ & $9,46^{\text {ns }}$ & $0,37^{* *}$ & $0,18^{* *}$ \\
\hline \multirow{2}{*}{ K. senegalensis } & $(0,041)$ & $(0,17)$ & $(1,02)$ & $(9,87)$ & $(0,26)$ & $(0,15)$ \\
\hline & 0,084 & 0,05 & 1,53 & 6,40 & 0,79 & 0,26 \\
& $(0,039)$ & $(0,04)$ & $(1,32)$ & $(5,64)$ & $(0,63)$ & $(0,16)$ \\
\hline
\end{tabular}

*DRL: Deformação residual longitudinal; IRTT: Índice de rachaduras de topo de toras; DM: Deslocamento de medula; IRTS: Índice de rachaduras de tábuas após secagem; ENC: Encurvamento; ARQ: Arqueamento.

Valores entre parênteses referem-se ao desvio padrão.

** e ns: As médias diferem e não diferem significativamente entre si em nível de $1 \%$ de probabilidade pelo teste $t$ de Student, respectivamente.

Destaca-se que as médias dos valores da DRL (Tabela 1) das duas espécies de mogno africano estão compreendidas entre 0,042 a 0,158 mm, faixa de variação observada em pesquisas com espécies do gênero Eucalyptus, entre as idades de 6 a 19 anos, plantados no Brasil. Mencionando, por exemplo, os trabalhos de Lima et al. (2004), Carvalho et al. (2010), Beltrame et al. (2013) e França (2014). Entretanto, as médias dessa variável, para as duas espécies do gênero Khaya, foram superiores ao valor $(0,062 \mathrm{~mm})$ observado por Delucis et al. (2014), para a madeira de acácia negra (Acacia mearnsii) aos sete anos de idade, e a média $(0,047 \mathrm{~mm})$ observada por Flórez (2012) para a madeira de teca (Tectona grandis), com 13 nos de idade.

Na seleção de árvores para serraria é interessante conhecer a relação da DRL com o DAP da árvore. Pois, o diâmetro é a variável mais empregada neste tipo de seleção, por interferir diretamente no rendimento produtivo, além da fácil mensuração em campo. 
Os valores de DRL não correlacionaram, significativamente, com os observados para as características dendrométricas (altura comercial e DAP) e deslocamento da medula das árvores para as duas espécies de mogno africano. É possível que, neste caso, a DRL esteja mais associada com os genótipos e níveis de alterações que as árvores sofreram ao longo do crescimento, em reposta à ação de cargas críticas (vento e peso da copa) sobre o fuste, inclinação do tronco, orientação da copa, competição entre árvores, variação do ângulo da grã da madeira e presença de lenho de reação, do que com o crescimento propriamente dito de suas dimensões. Ademais, o deslocamento da medula nas toras da base das espécies de Khaya foi pequeno, não havendo por isso efeito sobre as deformações residuais.

O aumento dos valores de DRL resultou em maiores índices de rachaduras de topo de toras, uma vez que, a correlação entre o IRTT e DRL foi positiva (Figura 2), apesar de não significativa, para ambas espécies de mogno africano. Resultado similar foi encontrado por França (2014), para a relação da DRL com as rachaduras de topo de toras de sete clones do híbrido de Eucalyptus grandis $x$ Eucalyptus urophylla aos 13 anos.

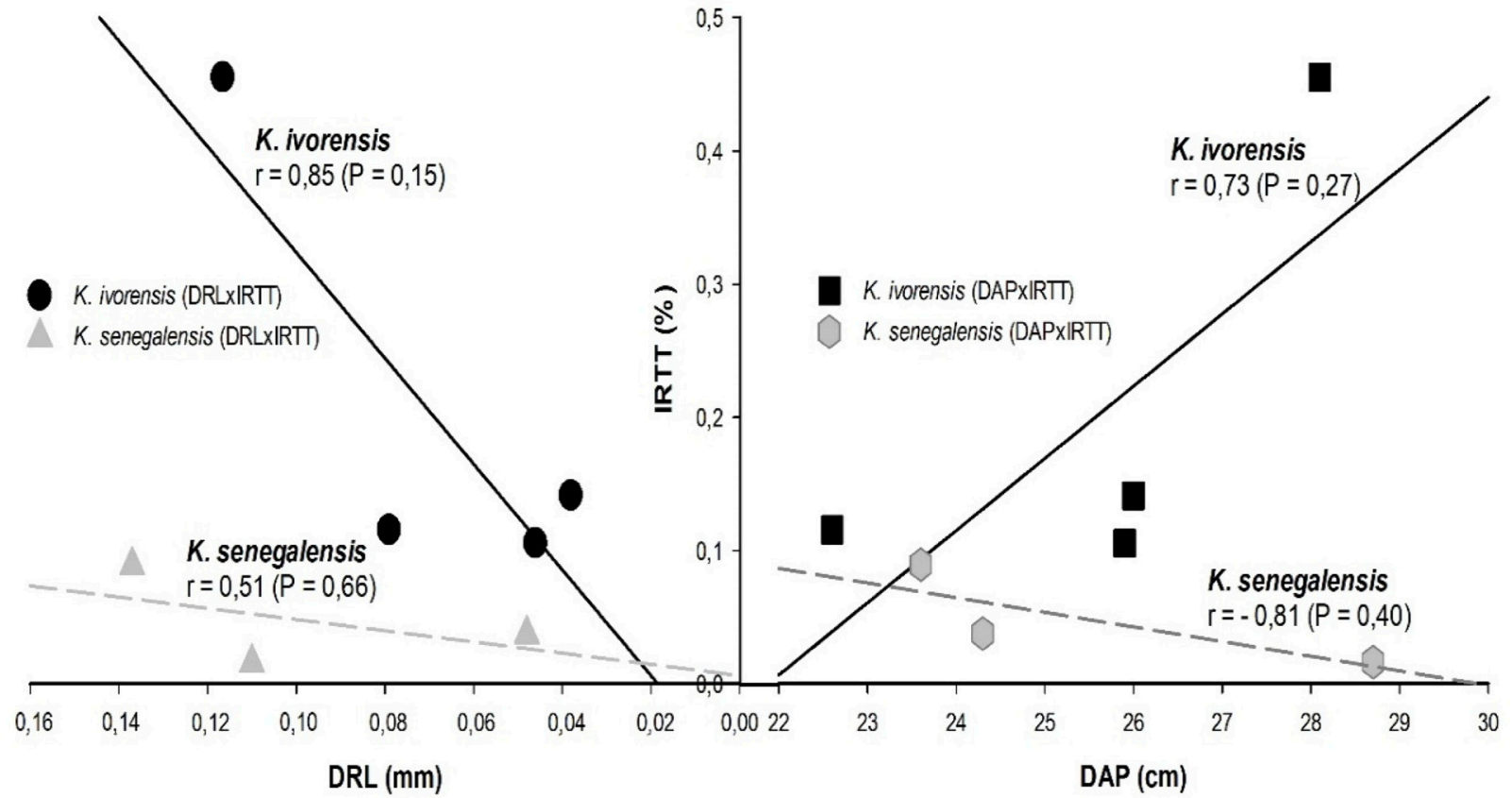

Figura 2. Diagrama de dispersão do índice de rachaduras de topo de toras (IRTT) com a deformação residual longitudinal (DRL) e o diâmetro à altura do peito (DAP) da $K$. ivorensis e $K$. senegalensis aos 19 anos de idade.

Figure 2. Scatter plots of the end splits of logs index (IRTT) with the longitudinal residual strain (LRS) and the diameter at breast height (DBH) of 19-year-old $K$. ivorensis and $K$. senegalensis.

Rachaduras de topo de toras e deslocamento da medula: as toras de K. ivorensis evidenciaram os maiores comprimentos de rachaduras de topo (diferença de 4,4 cm) e, consequentemente, a maior área deste defeito, comparada às toras de K. senegalensis. Entretanto, o IRTT das duas espécies não diferenciou-se estatisticamente (Tabela 1). A incidência deste defeito nas toras de mogno africano foi inferior a delimitada para toras de E. grandis, de 21 e 18 anos de idade, por Lima, Garcia e Stape (2007), e Trevisan et al. (2013), respectivamente.

As rachaduras de topo das toras de K. senegalensis, em sua totalidade, ocorreram em regiões mais próximas da medula, compostas por lenho juvenil. Esse mesmo defeito, para as toras de K. ivorensis, ocorreu tanto em regiões próximas à medula quanto à casca, perfazendo as zonas de lenho juvenil e adulto.

As médias do DAP das árvores de K. ivorensis apresentaram, apesar de não significativas, correlações medianas e positivas com o IRTT (Figura 2). Comportamento oposto foi observado para a espécie K. senegalensis, ou seja, à medida que aumentou o diâmetro das árvores reduziram-se os índices de rachaduras de topo. Apesar da semelhança do DAP das árvores, observada para as duas espécies de mogno africano, houve um comportamento diferente da relação DAP / IRTT para ambas. Ressalva-se que a pré-disposição genética de cada espécie para o desenvolvimento das rachaduras 
de topo das toras, provocadas pelas tensões de crescimento, pode ser um fator que, neste caso, influenciou em maior grau que o ambiente, níveis de crescimento e idade (ARMSTRONG et al., 2007).

A redução da proporção das rachaduras das toras de K. senegalensis, à medida que ocorre um incremento do diâmetro, é um ótimo e almejado predicado para a produção de madeira serrada. Toras mais cilíndricas, com maior diâmetro, poucas rachaduras de topo e com baixa deformação residual longitudinal tendem a produzir um maior rendimento em madeira serrada no desdobro, em virtude do menor índice de defeitos nas peças. Todavia, é importante considerar que, o maior diâmetro das toras, acompanhado de maior proporção de lenho juvenil e madeira de tração, propriedades físico-mecânicas inferiores e maior ângulo da grã, provavelmente, irão provocar um menor rendimento na produção e perda da qualidade da madeira serrada do gênero Khaya.

Para a situação em estudo, não houve diferenças significativas no deslocamento da medula (DM) entre as espécies (Tabela 1), apesar desta variável ser um pouco superior nas árvores de $K$. ivorensis. Isto significa que por estarem plantadas em um mesmo local plano, ocorreu, para ambas espécies, um crescimento mais simétrico do diâmetro com a medula mais centralizada, em reposta a menores inclinações do fuste e/ou baixa movimentação da copa provocada por ventos, nível de competição entre as árvores, efeitos do desbaste e mortalidade de indivíduos.

Todavia, para a madeira de K. senegalensis existiu uma correlação significativa, negativa e muito forte $(\mathrm{r}=-0,99 ; \mathrm{P}<0,05)$ entre o DM e a altura comercial, delineando um aumento da excentricidade da medula para árvores de menor altura. Esta relação indica que, tábuas desdobradas de árvores pequenas em altura poderão apresentar uma maior distorção e maior índice de desclassificação, por causa da presença de medula excêntrica, que libera as tensões de crescimento de forma desequilibrada (ARMSTRONG et al., 2007).

Rachaduras de topo de tábuas após a secagem: a madeira de K. ivorensis apresentou, visivelmente, o maior IRTS, comparada a madeira de K. senegalensis, apesar de não haver diferença significativa entre as médias (Tabela 1). Este resultado está diretamente interligado aos valores de DRL e IRTT, e a menor resistência mecânica e densidade da madeira de K. ivorensis.

Os maiores comprimentos de rachaduras de topo foram observados nas tábuas de $K$. ivorensis (59,33 mm), comparada a madeira de K. senegalensis $(31,62 \mathrm{~mm})$, o que evidencia que as tábuas tangenciais de maiores dimensões [Figura 1 (D)] foram mais propensas a rachar, em virtude da baixa resistência à magnitude das tensões de crescimento, maior relação entre o comprimento da rachadura e a largura da tábua, e maiores contrações no sentido da largura da peça. Destaca-se que 21,6\% das tábuas de K. senegalensis e 6,9\% das tábuas de K. ivorensis não apresentaram rachaduras.

O IRTS das duas espécies de mogno africano foi inferior aos índices, 16,06 e 26,24\%, observados em tábuas de híbridos de Eucalyptus (13 a 17 anos) e o híbrido E. urophylla $\mathrm{x}$ E. grandis (13 anos) nas pesquisas de Caixeta et al. (2002); França (2014), respectivamente.

Observa-se uma associação do IRTT com o IRTS, pois na espécie com as maiores dimensões de rachaduras de topo das toras, também ocorreu os maiores comprimentos das rachaduras das tábuas. O efeito da magnitude das tensões consolidada como rachaduras de topo das toras, tem consequência mais direta nos defeitos da madeira serrada do que a DRL, uma vez que houve uma analogia da média desta última variável entre as espécies (Tabela 1).

Desta maneira, entre os métodos para avaliar os efeitos das tensões sobre a qualidade da madeira serrada, destacou-se a mensuração das rachaduras de topo de toras após o corte das árvores. Pois, o método de medição das deformações periféricas, não informa a magnitude e a distribuição radial das tensões longitudinais no interior do tronco (LIMA et al., 2004). Além disto, a seleção de árvores para serraria, avaliando-se as rachaduras de topo das toras, pode possibilitar a prevenção deste mesmo defeito nas tábuas (LIMA; GARCIA; PIEDADE, 2002) mas, recomenda-se a conciliação com o conhecimento das propriedades intrínsecas e resistência mecânica do lenho, processos de desdobro e secagem otimizados.

Empenamentos das tábuas após o processo de secagem: as tábuas de K. ivorensis apresentaram os menores índices de encurvamento e arqueamento (Tabela 1), atendendo ao limite estabelecido pela NBR 9487 (ABNT, 1986). Apenas para o arqueamento, as tábuas de K. senegalensis apresentaram valores menores a $0,5 \%$ em relação ao comprimento total da tábua, limite da norma referida.

A madeira de $K$. senegalensis possuiu as maiores flechas de encurvamento (diferença de 4,16 $\mathrm{mm} / \mathrm{m}$ ) e arqueamento (diferença de $0,78 \mathrm{~mm} / \mathrm{m}$ ) comparada a madeira de K. ivorensis. As médias 
das flechas desses empenamentos foram, na maioria dos casos, inferiores quantitativamente e superiores qualitativamente às médias observadas para tábuas de K. senegalensis, com 32 anos de idade, provenientes de plantios na Austrália (ARMSTRONG et al., 2007).

Assim, é possível prever um maior percentual de perdas em volume das tábuas de K. senegalensis na operação de aplainamento, visto que, para eliminar o encurvamento, haverá uma redução da espessura e, para o arqueamento, a redução ocorrerá na largura das tábuas. Destaca-se, também, que a manifestação do arqueamento pode estar mais associada às tensões ainda presentes nas tábuas do que ao processo de secagem (MATOS et al., 2003).

Além das propriedades abordadas para cada espécie, os índices de rachaduras e empenamentos também podem ser atribuídos a inclinações e irregularidades da grã, variações do ângulo microfibrilar, dificuldade de secagem e presença de madeira de tração (SIMPSON, 1991; WALKER, 2006).

Durante o desdobro, ao retirar uma costaneira e a primeira tábua (bordaneira), o movimento (deflexão) do semibloco, pela adaptação à nova distribuição residual das tensões, é muitas vezes um indicador de que as tábuas posteriores serradas da tora, terão níveis relativamente altos de distorção, implicando na perda de uniformidade da espessura e empenamentos (GARCIA, 1995; ARMSTRONG et al., 2007).

Nota-se que as tábuas da espécie que rachou mais empenou menos (Tabela 1), isto demonstra que a intensidade da deformação é dependente da rigidez da madeira. Nessa premissa, as forças de deformação que provocaram as rachaduras foram se transformando gradualmente, em forças que geraram os empenamentos (LIMA et al., 2006). Por isso, é necessário adotar critérios de sobremedidas, considerando as dimensões nominais do produto final, pois as perdas com defeitos no desdobro e na secagem, decorrentes das tensões de crescimento, poderão influenciar a utilização das peças e a relação custo/benefício da produção.

Propriedades físicas da madeira: não houve correlações significativas das propriedades físicas da madeira com a DRL, IRTT e DM (Tabela 2) para as duas espécies, sendo a maioria das correlações negativas. A madeira de K. ivorensis apresentou os menores valores de DB e CV, 0,43 $\mathrm{g} \mathrm{cm}^{-3}$ e 9,3\%, comparada com a madeira de K. senegalensis, $0,57 \mathrm{~g} \mathrm{~cm}^{-3}$ e $11,86 \%$, respectivamente.

Tabela 2. Coeficiente de correlação de Pearson entre a deformação residual longitudinal, o índice de rachaduras de topo de toras, o deslocamento da medula e as propriedades físicas da madeira de $K$. ivorensis e K. senegalensis aos 19 anos de idade.

Table 2. Pearson's correlation coefficient between the longitudinal residual strain, the end splits of logs index, displacement of the pith and physical properties of the wood of 19-year-old $K$. ivorensis and $K$. senegalensis.

\begin{tabular}{lcccc}
\hline Espécie & Variáveis & ${ }^{*}$ DRL & IRTT & DM \\
\hline \multirow{3}{*}{ K. ivorensis } & \multirow{2}{*}{ DB } & $-0,49$ & $-0,47$ & $-0,73$ \\
& & $(0,51)$ & $(0,53)$ & $(0,27)$ \\
\cline { 2 - 5 } & \multirow{2}{*}{$\mathrm{CV}$} & $-0,85$ & $-0,95$ & $-0,10$ \\
& & $(0,15)$ & $(0,053)$ & $(0,90)$ \\
\hline \multirow{3}{*}{ K. senegalensis } & \multirow{2}{*}{$\mathrm{DB}$} & $-0,70$ & $-0,97$ & 0,80 \\
& & $(0,50)$ & $(0,16)$ & $(0,41)$ \\
\cline { 2 - 5 } & \multirow{2}{*}{$\mathrm{CV}$} & $-0,32$ & 0,65 & $-0,90$ \\
\end{tabular}

*DRL: Deformação residual longitudinal; IRTT: Índice de rachaduras de topo de toras; DM: Deslocamento de medula; DB: Densidade básica; CV: contração volumétrica.

Valores entre parênteses referem-se ao valor $P$.

Para a madeira de K. senegalensis, foi observada uma correlação forte e negativa entre os valores de IRTT e DB, e uma correlação mediana e positiva entre o IRTT e CV, indicando uma maior propensão de índices de rachaduras de topo das toras com a diminuição dos valores de densidade e o aumento da contração volumétrica da madeira (Tabela 2).

A diferença nos valores de CV da madeira, tanto por anisotropia quanto por gradientes de umidade desenvolvidos na peças durante a secagem, é uma das variáveis que pode ter contribuído no incremento dos índices de empenamentos das tábuas. Analisando o modelo de corte adotado no desdobro das toras e a variação radial da CV na madeira de mogno africano, esta informação fica mais visível (Figura 3).

Ponderando que o modelo de corte das toras [Figura 3 (A)] produziu um pranchão central (8 $\mathrm{cm})$ e quatro tábuas tangenciais $(2,5 \mathrm{~cm})$, e que a espessura do fio de corte foi cerca de $0,9 \mathrm{~cm}$, as tá- 
buas das duas espécies de mogno africano foram desdobradas em regiões com picos de variação de contração volumétrica [Figura 3 (B)]. Destacando a espécie K. senegalensis, as tábuas desdobradas, próximas ao pranchão central, apresentaram uma variabilidade na CV ao longo da sua espessura [Figura 3 (B)]. Essa variável pode ter contribuído em magnitude para as maiores distorções nas tábuas desta espécie, analisadas na forma de encurvamento e arqueamento.

(A)

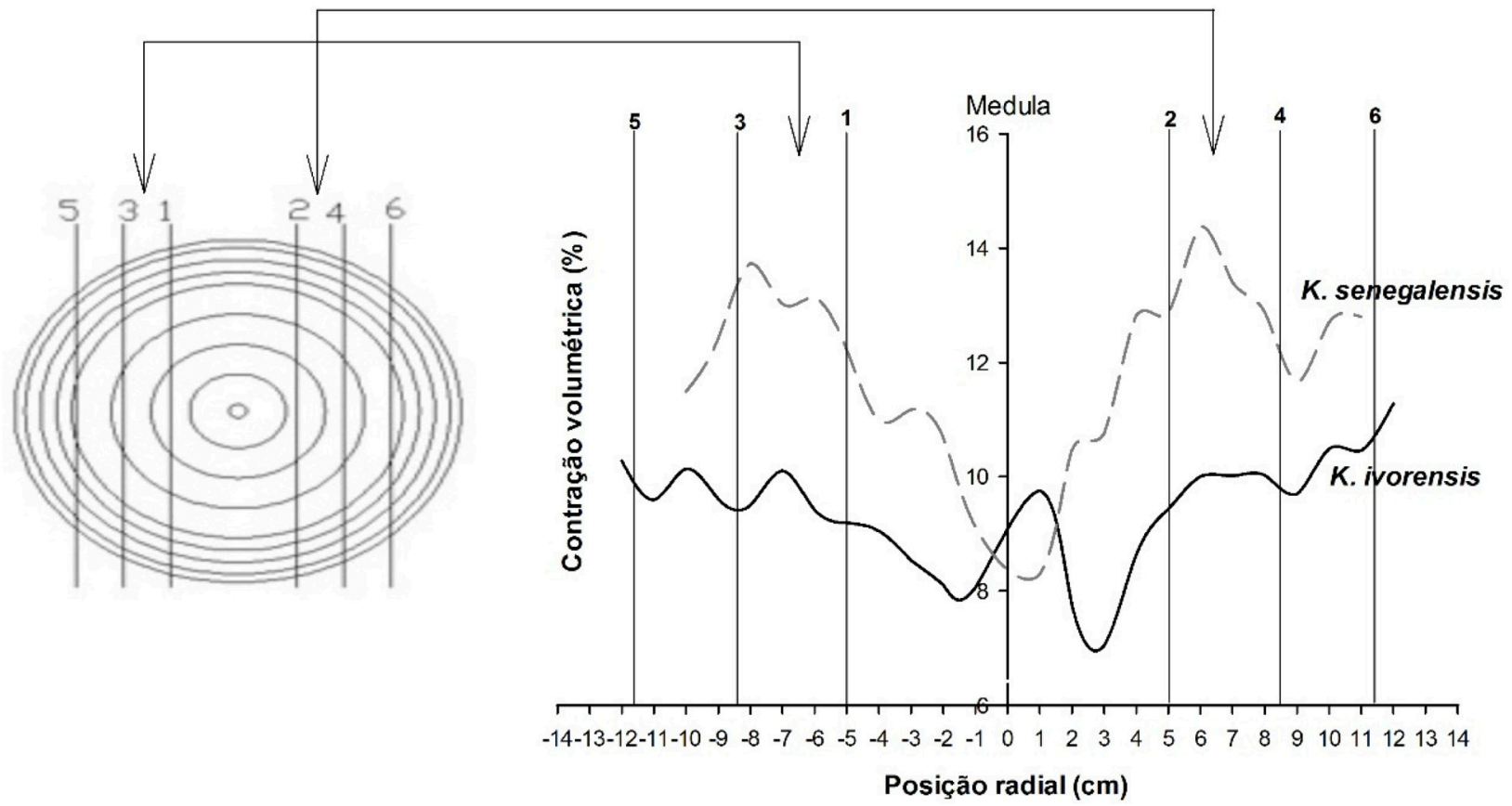

Figura 3. Relação do modelo de corte (A) com a variação média da contração volumétrica (B) da $K$. ivorensis e K. senegalensis aos 19 anos de idade.

Figure 3. Relationship of the sawing diagram (A), with the mean variation in volumetric shrinkage (B) of 19-year-old $K$. ivorensis and $K$. senegalensis.

\section{CONCLUSÕES}

Os níveis de deformação residual longitudinal, rachaduras de topo de toras e tábuas, e deslocamento de medula, foram semelhantes entre as espécies de K. ivorensis e K. senegalensis.

Os valores de deformação residual longitudinal não tiveram relações com o diâmetro na altura do peito das árvores. Houve relações positivas, apesar de não significativas, de incremento do índice de rachaduras de topo das toras com o aumento da deformação residual longitudinal.

As tábuas de K. senegalensis apresentaram os maiores índices de empenamentos e as toras e tábuas de $K$. ivorensis, as maiores dimensões de rachaduras de topo.

Os índices das variáveis avaliadas não são elevados ao ponto de inviabilizar o uso e a qualidade das duas espécies de mogno africano para a produção de madeira serrada. Porém, é importante ponderar a forma e dimensões das árvores, os níveis de encurvamento das tábuas para a espécie $K$. senegalensis, a relação da deformação residual longitudinal com as rachaduras de topo das toras e os defeitos da madeira serrada em regiões mais próximas a medula e em idades mais jovens. A mesma cautela deverá ser observada para as técnicas de beneficiamento e secagem da madeira, e para os efeitos das características de manejo e locais de plantio.

Como desafio atual e futuro, há a necessidade da realização de programas de melhoramento genético e da adoção de técnicas de silvicultura e manejo das florestas plantadas de mogno africano, alinhados a investigação dos seus efeitos nas características do fuste e nos principais defeitos das toras e da madeira serrada. 


\section{AGRADECIMENTOS}

Ao Departamento de Ciências Florestais e da Madeira e ao PPG em Ciências Florestais da UFES, a Fundação de Amparo à Pesquisa e Inovação do Espírito Santo - FAPES, a empresa VALE pela bolsa-auxílio, a Reserva Natural Vale pelo material e condições de pesquisa, ao Técnico Florestal Jonacir Souza e ao Engenheiro Florestal Gilberto Terra.

\section{REFERÊNCIAS BIBLIOGRÁFICAS}

ABNT - ASSOCIAÇÃO BRASILEIRA DE NORMAS TÉCNICAS. NBR 7190: Projeto de estruturas de madeira. Rio de Janeiro, 1997. 107 p.

ABNT - ASSOCIAÇÃO BRASILEIRA DE NORMAS TÉCNICAS. NBR 9487: Classificação da madeira serrada de folhosas. Rio de Janeiro, 1986. $32 \mathrm{p}$.

ARMSTRONG, M.; REILLY, D. F.; LELIEVRE, T.; HOPEWELL, G.; REDMAN, A.; FRANCIS, L; ROBERTSON, R. M. African Mahogany grown in Australia - Wood quality and potential uses. Barton: RIRDC, 2007. 94 p.

BELTRAME, R.; MATTOS, B. D.; HASELEIN, C. R.; SANTINI, E. J.; GATTO, D. A.; CADEMARTORI, P. H. G.; PEDRAZI, C. Evaluation of longitudinal residual strain of Eucalyptus saligna Smith. Wood. Scientia Forestalis, Piracicaba, v. 41, n. 97, p. 95-101, 2013.

BOX, G. E. P.; COX, D. R. An analysis of transformation. Journal of the Royal Statistical Society, London, v. 26, n. 2, p. 211-243, 1964.

CAIXETA, R. P.; TRUGILHO, P. F.; LIMA, J. T.; ROSADO, S. C. S. Classificação de Eucalyptus relacionados com a qualidade da madeira após a secagem natural. Scientia Forestalis, Piracicaba, n. 61, p. 49-58, 2002.

CARVALHO, A. M.; GONÇALVES, M. P. M.; AMPARADO, K. F.; LATORRACA, J. V. F.; GARCIA, R. A. Correlações da altura e diâmetro com tensões de crescimento em árvores de Corymbia citriodora e Eucalyptus urophylla. Revista Árvore, Viçosa, v. 34, n. 2, p. 323-331, 2010.

DELUCIS, R. A.; MISSIO, A. L.; BELTRAME, R.; GATTO, D. A. Predição da Deformação Residual Longitudinal por meio de propriedades dendrométricas e físicas de Acácia negra. Ciência da Madeira, Pelotas, v. 05, n. 01, p. 42-57, 2014.

FLÓREZ, J. B. Caracterização tecnológica da madeira jovem de teca (Tectona grandis L. f.). 2012. 85 p. Dissertação (Mestrado em Ciência e Tecnologia da Madeira) - Universidade Federal de Lavras, Lavras, 2012.

FRANÇA, F. J. N. Propriedades da madeira de eucalipto para a produção de madeira serrada. 2014. 61 p. Dissertação (Mestrado em Ciências Florestais) - Universidade Federal do Espírito Santo, Jerônimo Monteiro, 2014.

GARCIA, J. N. Técnicas de desdobro de eucalipto. In: SEMINÁRIO INTERNACIONAL DE UTILIZAÇÃO DA MADEIRA DE EUCALIPTO PARA SERRARIA, 1995, São Paulo. Anais... Piracicaba: IPEF, 1995, p. 59-67.

LIMA, I. L.; GARCIA, J. N.; PIEDADE, S. M. S. Rachaduras de extremidades de tora e suas implicações nas rachaduras da madeira serrada. Scientia Forestalis, Piracicaba, n. 61, p. 13-24, 2002.

LIMA, I. L.; GARCIA, J. N.; STAPE, J. L. Influência do Desbaste e da Fertilização no Deslocamento da Medula e Rachaduras de Extremidade de Tora de Eucalyptus grandis Hill ex-Maiden. Cerne, Lavras, v. 13, n. 2, p. 170$177,2007$. 
Silva et al. - Qualidade da madeira de mogno africano para a produção de serrados

LIMA, I. L.; GARCIA, J. N.; STAPE, J. L.; PIEDADE, S. M. S. Efeito do desbaste e da fertilização nas tensões de crescimento em Eucalyptus grandis. Scientia Forestalis, Piracicaba, n. 70, p. 171-183, 2006.

LIMA, J. T.; TRUGILHO, P. F.; ROSADO, S. C. S.; CRUZ, C. R. Deformações Residuais Longitudinais decorrentes de tensões de crescimento em eucaliptos e suas associações com outras propriedades. Revista Árvore, Viçosa, v. 28, n. 1, p. 107-116, 2004.

MATOS, J. L. M.; IWAKIRI, S.; ROCHA, M. P.; PAIM, R. M.; ANDRADE, L. O. Redução do efeito das tensões de crescimento em toras de Eucalyptus dunnii. Scientia Forestalis, Piracicaba, n. 64, p. 128-135, 2003.

SCHAITZA, E. G.; MATTOS, P. P.; PEREIRA, J. C. D. Metodologias simples e baratas para análise de Imagens planas. Colombo: EMBRAPA, 2003. 4 p. (Comunicado técnico, 90)

SIMPSON, W. T. Dry Operator's Manual. Madison: Forest Products Laboratory, 1991, 274 p.

TREVISAN, R.; DENARDI, L.; CARDOSO, G. V.; HASELEIN, C. R.; SANTINI, E. J. Variação axial do índice de rachaduras na base e no topo de toras de Eucalyptus grandis W. Hill ex Maiden. Scientia Forestalis, Piracicaba, v. 41, n. 97 , p. $75-81,2013$.

WALKER, J. C. F. Primary Wood Processing: Principles and Practice. 2.ed. Springer, 2006, 595 p.

Recebido em 12/11/2014

Aceito para publicação em 12/08/2015 